\title{
Obesity Is Associated With Increasing Esophageal Acid Exposure in Korean Patients With Gastroesophageal Reflux Disease Symptoms
}

\author{
Hee Sun Jung, Myung Gyu Choi,* Myong Ki Baeg, Chul Hyun Lim, Jin Soo Kim, Yu Kyung Cho, In Seok Lee, Sang Woo \\ Kim and Kyu Yong Choi
}

Division of Gastroenterology, Department of Internal Medicine, College of Medicine, Seoul St. Mary's Hospital, The Catholic University of Korea, Seoul, Korea

\section{Background/Aims}

Obesity is regarded as an important contributor to the increasing occurrence of gastroesophageal reflux disease. The aims of this study were to determine whether obesity is associated with gastroesophageal reflux in patients with gastroesophageal reflux disease and to identify the factors affecting increased acid exposure in obese patients.

\section{Methods}

We retrospectively analyzed the data of patients who underwent ambulatory 24-hour pH monitoring and esophageal manometry at Seoul St. Mary's Hospital. Obesity was classified according to the Asia-Pacific criteria.

\section{Results}

A total of 366 patients were analyzed; 18 were underweight, 152 normal weight, 104 overweight, and 92 obese. Obesity was more frequent in men and younger patients. The percentage time of $\mathrm{pH}<4$ in the total, upright, and postprandial periods was significantly higher in obese patients than in normal or underweight patients. The DeMeester score was also higher in obese patients. Body mass index correlated positively with reflux parameters. Multivariate analysis showed that being male and obesity were significantly associated with abnormal acid exposure $(P<0.005)$. The total lower esophageal sphincter length shortened as body mass index increased $(P<0.005)$. The gastroesophageal pressure gradient increased as body mass index increased $(P<0.05)$.

\section{Conclusions}

Obesity is associated with increasing esophageal acid exposure. The mechanism responsible for the relationship between gastroesophageal reflux disease and obesity may be associated with shortening of the lower esophageal sphincter length and increasing the gastroesophageal pressure gradient.

(J Neurogastroenterol Motil 2013;19:338-343)

\section{Key Words}

Esophageal pH monitoring; Gastroesophageal reflux disease; Manometry; Obesity

Received: January 15, 2013 Revised: April 11, 2013 Accepted: April 13, 2013

(c) This is an Open Access article distributed under the terms of the Creative Commons Attribution Non-Commercial License (http://creativecommons. org/licenses/by-nc/3.0) which permits unrestricted non-commercial use, distribution, and reproduction in any medium, provided the original work is properly cited.

*Correspondence: Myung Gyu Choi, MD, PhD

Division of Gastroenterology, Department of Internal Medicine, College of Medicine, Seoul St. Mary's Hospital, The Catholic University of Korea, 222, Banpo-daero, Seoucho-gu, Seoul 137-701, Korea

Financial support: None. Tel: +82-2-2258-6017, Fax: +82-2-2258-2089, E-mail: choim@catholic.ac.kr

Conflicts of interest: None.

Author contributions: Hee Sun Jung analyzed data and wrote the manuscript. Myung Gyu Choi designed organized and mediated the present study and supervised the manuscript. Myong Ki Baeg, Chul Hyun Lim and Jin Soo Kim helped analysis of data. Yu Kyung Cho, In Seok Lee, Sang Woo Kim and Kyu Yong Choi revised the manuscript and advised design of study. 


\section{Introduction}

The prevalence of gastroesophageal reflux disease (GERD) has been increasing in Korea. ${ }^{1}$ One important factor causing this increase is the prevalence of obesity, which has increased in Korea in the past few decades. ${ }^{2-4}$ Several studies support an association between obesity and endoscopic erosive esophagitis. ${ }^{5,6}$ However, contrasting results have also been reported in different target groups and with different diagnostic criteria. ${ }^{6-12}$

The reason why GERD is common in obese patients is uncertain, and several mechanisms are suspected. ${ }^{10,13-15}$ Central obesity could raise intragastric pressure, causing predisposition for reflux. There appears to be a dose-dependent relationship between GERD and obesity; that is, the higher the body mass index (BMI) and waist circumference, the greater the intragastric pressure and gastroesophageal pressure gradient (GEPG). Obesity is a significant independent risk factor for hiatal hernia, especially in Caucasians. ${ }^{16}$ Recent manometry studies suggest that the pressure morphology within and across the esophagogastric junction is altered in obesity; for example, obesity increases intragastric pressure and the GEPG during the inspiratory phase of respiration. Obesity is associated with an increased frequency of transient lower esophageal sphincter (LES) relaxation and increased acid exposure. ${ }^{10}$ Acid exposure times and other parameters of ambulatory $\mathrm{pH}$ monitoring are significantly greater in obese people compared with overweight and normal weight individuals in the Caucasian population. ${ }^{11,12}$

The aims of this study were to determine whether obesity is associated with increased acid exposure in Korean patients with GERD and to identify factors affecting increased acid exposure in obese patients.

\section{Materials and Methods}

\section{Subjects}

We retrospectively analyzed the data of GERD patients who underwent ambulatory 24-hour $\mathrm{pH}$ monitoring and esophageal manometry from August 2001 to December 2008 in Seoul St. Mary's Hospital in Korea. Indications for $\mathrm{pH}$ monitoring included (1) patients who have reflux symptoms and a normal endoscopy, (2) patient who have suspected extraesophageal symptoms of GERD and (3) before fundoplication to ensure the presence of pathologic reflux and (4) patients who were referred due to suspected GERD. The key exclusion criteria were a history of gastric surgery, uncontrolled diabetes mellitus, stroke, achalasia or diffuse esophageal spasm, or concomitant peptic ulcer. We also excluded patients who were on antireflux medication at the time of examination.

\section{Methods}

All patients were given a self-administered validated questionnaire about reflux symptoms. ${ }^{1}$ The questionnaire included questions about demographic characteristics, the frequency and severity of typical and atypical symptoms, medical or surgical history, and psychosomatic score. BMI was calculated as the ratio of weight $(\mathrm{kg})$ to the square of height $\left(\mathrm{m}^{2}\right)$ and was then classified according to the Asia-Pacific criteria as underweight (BMI < $\left.18.5 \mathrm{~kg} / \mathrm{m}^{2}\right)$, normal $(18.5 \leq \mathrm{BMI}<23)$, overweight $(23 \leq$ BMI $<25)$ and obese $(\mathrm{BMI} \geq 25)$.

Twenty-four-hour esophageal $\mathrm{pH}$ monitoring was performed using an antimony $\mathrm{pH}$ catheter. Before the $\mathrm{pH}$ monitoring, patients were instructed to discontinue taking proton pump inhibitors and histamin 2 receptor antagonists for a minimum of 7 days and antacid for 48 hours. The $\mathrm{pH}$ sensor was placed $5 \mathrm{~cm}$ above the proximal margin of the LES, as determined by esophageal manometry. Patients were instructed to record the time of their meals and sleep, and any symptoms during the examination. We calculated the percentage time of $\mathrm{pH}<4(\%$ time of $\mathrm{pH}<$ 4 ) using the following equation: minutes with $\mathrm{pH}<4$ /monitoring time (in minutes) $\times 100$ for the total, upright, supine, and postprandial periods. Abnormal acid exposure was defined as the percentage time of $\mathrm{pH}<4$ (\% time of $\mathrm{pH}<4$ ) in total period greater than $4.5 \%$.

Esophageal manometry was performed using an eight-channel impedance manometric catheter (Sandhill Scientific, Highlands Ranch, CO, USA). Both perfused and solid state systems were used in this study. We measured the maximum LES pressure, GEPG, LES length and intra-abdominal LES length. We measured LES length as distance between the upper and lower border of the LES. Upper border of the LES is where the pressure drops to intrathoracic baseline pressure. Lower border of the LES is where the pressure exceeds the gastric baseline pressure by $2 \mathrm{mmHg}$ or more. The intra-abdominal length of the LES is defined as the distance between the respiratory inversion point and the lower border of the LES. GEPG was calculated as the difference between mean intragastric pressure and intraesophageal pressure. Intraesophageal pressure was measured in the signal derived from the distal esophageal pressure sensor 5 
$\mathrm{cm}$ proximal to the border of the LES.

The study protocols were reviewed and approved by the institutional Research Board at Seoul St. Mary's Hospital (IRB No. KC10RASI0664).

\section{Statistical Methods}

We used independent-sample $t$ tests and analysis of variance for univariate analysis of single variables. Logistic regression analysis was used for multivariate analysis of factors related to increased esophageal acid exposure. A $P$-value $<0.05$ was considered significant. Statistical calculations were performed using SPSS for Windows software (version 17.0; IBM, Armonk, NY, USA).

\section{Results}

\section{Patient Characteristics}

A total of 366 patients were included in this study; 156 men
(42.6\%) and 210 women (57.4\%) with mean age of 51 years and mean BMI of $23.0 \mathrm{~kg} / \mathrm{m}^{2}$. According to the Asian-Pacific criteria for obesity, 18 were underweight, 152 normal weight, 104 overweight, and 92 obese. The demographic characteristics of the 4 groups are summarized in Table 1 . There were no differences in symptoms between the 4 groups. Overweight and obesity were observed more frequently in men. Underweight patients were younger than obese patients. Educational level was lower in obese patients than in the normal weight group.

\section{Association Between Esophageal Acid Exposure and Body Mass Index}

The percentage of the total time of $\mathrm{pH}<4$ was higher in obese patients than in normal weight or underweight patients. A linear trend was noted between percentage of the total time of $\mathrm{pH}$ $<4$ and BMI $(P<0.005)$. The percentage of the time of $\mathrm{pH}$ $<4$ in the upright and postprandial periods was significantly higher in obese group compared with other groups; this was not

Table 1. Demographic Characteristics of Patients

\begin{tabular}{|c|c|c|c|c|c|}
\hline & $\begin{array}{l}\text { Underweight } \\
\qquad(\mathrm{n}=18)\end{array}$ & $\begin{array}{l}\text { Normal body weight } \\
\qquad(\mathrm{n}=152)\end{array}$ & $\begin{array}{l}\text { Overweight } \\
(\mathrm{n}=104)\end{array}$ & $\begin{array}{l}\text { Obesity } \\
(\mathrm{n}=92)\end{array}$ & $P$-value \\
\hline $\mathrm{BMI}\left(\right.$ mean $\left.\pm \mathrm{SD}, \mathrm{kg} / \mathrm{m}^{2}\right)$ & $17.1 \pm 1.5$ & $21.1 \pm 1.1$ & $23.8 \pm 0.5$ & $26.7 \pm 1.6$ & $<0.005$ \\
\hline Age (mean $\pm \mathrm{SD}, \mathrm{yr})$ & $40.4 \pm 13.6$ & $49.6 \pm 13.3$ & $52.6 \pm 9.5$ & $53.9 \pm 10.5$ & $<0.005$ \\
\hline Male gender (n [\%]) & $5(27.8)$ & $50(32.9)$ & $53(51.0)$ & $48(52.2)$ & $<0.005$ \\
\hline Heartburn (n [\%]) & $14(77.8)$ & $86(58.1)$ & $65(63.7)$ & $48(55.8)$ & NS \\
\hline Acid regurgitation (n [\%]) & $8(44.4)$ & $51(34.2)$ & $32(31.1)$ & $36(41.9)$ & NS \\
\hline Globus (n [\%]) & $7(36.8)$ & $76(50.0)$ & $48(47.1)$ & $43(47.8)$ & NS \\
\hline Hoarseness (n [\%]) & $7(36.8)$ & $68(45.0)$ & $46(45.1)$ & $41(45.1)$ & NS \\
\hline Cough (n [\%]) & $9(47.4)$ & $58(38.2)$ & $36(35.0)$ & $32(35.6)$ & NS \\
\hline Coffee (n [\%]) & $10(52.6)$ & $74(51.0)$ & $58(59.2)$ & $55(63.2)$ & NS \\
\hline Current smoker (n [\%]) & $5(27.8)$ & $29(20.1)$ & $27(27.8)$ & $26(29.5)$ & NS \\
\hline LA Class $\geq$ LA-A (n [\%]) & $5(27.8)$ & $18(11.8)$ & $14(13.5)$ & $20(21.7)$ & NS \\
\hline Education grade $\geq$ university (n [\%]) & $11(64.7)$ & $73(51.8)$ & $34(34.0)$ & $29(33.7)$ & $<0.005$ \\
\hline
\end{tabular}

BMI, body mass index; LA, Los Angeles.

Table 2. Results of Ambulatory 24-hour pH Monitoring According to the Body Mass Index

\begin{tabular}{|c|c|c|c|c|c|c|}
\hline & & $\begin{array}{l}\text { Underweight } \\
\qquad(\mathrm{n}=18)\end{array}$ & $\begin{array}{l}\text { Normal body weight } \\
\qquad(\mathrm{n}=152)\end{array}$ & $\begin{array}{l}\text { Overweight } \\
(\mathrm{n}=104)\end{array}$ & $\begin{array}{l}\text { Obesity } \\
(\mathrm{n}=92)\end{array}$ & $P$-value \\
\hline \multirow[t]{4}{*}{$\%$ time $\mathrm{pH}<4($ mean $\pm \mathrm{SD}, \%)$} & Total & $1.01 \pm 1.02$ & $2.12 \pm 2.34$ & $2.71 \pm 2.81$ & $3.09 \pm 3.51$ & $<0.05$ \\
\hline & Upright & $1.45 \pm 1.16$ & $2.85 \pm 2.91$ & $4.07 \pm 4.36$ & $4.38 \pm 4.43$ & $<0.005$ \\
\hline & Supine & $0.25 \pm 0.49$ & $0.76 \pm 2.74$ & $0.42 \pm 1.02$ & $0.83 \pm 4.36$ & NS \\
\hline & Postprandial & $2.05 \pm 2.28$ & $4.10 \pm 5.14$ & $5.73 \pm 6.06$ & $6.20 \pm 7.10$ & $<0.005$ \\
\hline \multicolumn{2}{|l|}{ DeMeester score $($ mean $\pm \mathrm{SD})$} & $4.60 \pm 3.40$ & $8.90 \pm 9.20$ & $10.90 \pm 9.90$ & $12.00 \pm 14.70$ & $<0.05$ \\
\hline \multicolumn{2}{|c|}{ Number of long refluxes $>5$ min, total $($ mean $\pm \mathrm{SD})$} & $0.33 \pm 0.49$ & $1.24 \pm 1.79$ & $1.43 \pm 2.17$ & $1.49 \pm 2.20$ & NS \\
\hline \multicolumn{2}{|c|}{ Duration of longest reflux, total (mean $\pm \mathrm{SD}, \min )$} & $4.78 \pm 2.56$ & $7.38 \pm 6.82$ & $8.46 \pm 9.37$ & $8.14 \pm 7.78$ & NS \\
\hline
\end{tabular}


observed in the supine period (Table 2). Acid reflux in the upright and postprandial periods correlated positively with the BMI $(P<0.005$ for each). The DeMeester score was also higher in the obese patients than in the normal and underweight patients, and showed a linear association with obesity $(P<0.005)$.

In our study, abnormal acid exposure was defined as $>4.5$ in $\%$ time of $\mathrm{pH}<4$ in total period. Using this criterion, ${ }^{17}$ obesity was associated with a $1.94(P=0.049)$ increased likelihood of abnormal acid exposure compared with normal BMI. Abnormal acid exposure in the upright period only was defined as $>8.4 \%$ time of $\mathrm{pH}<4$; using this criterion, ${ }^{17}$ obesity was associated with a 3.35 -fold $(P=0.011)$ increased likelihood of abnormal acid exposure compared with normal BMI. If abnormal acid exposure was defined as DeMeester score greater than 14.72 , obesity was associated with a 1.90 -fold $(P=0.046)$ increased likelihood of abnormal acid exposure compared with normal BMI.

Demographic characteristics were compared between the normal and abnormal acid exposure groups (Table 3). Abnormal acid exposure was defined as $>4.5$ in $\%$ time of $\mathrm{pH}<4$ in total period. ${ }^{17}$ The univariate analysis showed a significant association between abnormal acid exposure and being male, having a high $\mathrm{BMI}$, and being a current smoker $(P<0.05)$. Multivariate regression analysis showed that being male (OR, 2.23; 95\% CI, $1.17-4.22)$ and obesity (OR, 1.41; 95\% CI, 1.02-1.95) were independently associated with increased esophageal acid exposure (Table 4).

\section{Esophageal Manometry Findings in Patients Grouped According to Body Mass Index}

There was no difference in the LES pressure between the 4 groups (Table 5). The total LES length shortened as BMI increased $(P=0.002)$, whereas the intra-abdominal LES length did not differ between the 4 groups. The GEPG increased as BMI increased $(P=0.048)$. There were same correlations in these 4 parameters of manometry between 2 groups classified by $\mathrm{BMI}$, underweight normal BMI group versus overweight obesity group.

Table 3. Comparison of Demographic Data Between Normal and Abnormal Exposure Groups

\begin{tabular}{|c|c|c|c|}
\hline & $\begin{array}{c}\text { Abnormal acid } \\
\text { Exposure }(-)(n=305)\end{array}$ & $\begin{array}{c}\text { Abnormal acid } \\
\text { Exposure }(+)(n=61)\end{array}$ & $P$-value \\
\hline Age (mean $\pm \mathrm{SD}, \mathrm{yr})$ & $50.7 \pm 11.7$ & $52.9 \pm 11.8$ & NS \\
\hline Male gender (n [\%]) & $117(38.4)$ & $39(63.9)$ & $<0.05$ \\
\hline Alcohol > 1 bottle, soju/wk (n [\%]) & $46(15.1)$ & $12(19.7)$ & NS \\
\hline Coffee drinker (n [\%]) & $154(50.5)$ & $40(65.6)$ & NS \\
\hline Current smoker (n [\%]) & $65(21.3)$ & $23(37.7)$ & $<0.05$ \\
\hline \multicolumn{4}{|l|}{ BMI group (n [\%]) } \\
\hline Underweight & $18.0(5.9)$ & $0.0(0.0)$ & $<0.05$ \\
\hline Normal & $133.0(43.6)$ & $19.0(31.1)$ & \\
\hline Overweight & $82.0(26.9)$ & $22.0(36.1)$ & \\
\hline Obesity & $72.0(23.6)$ & $20.0(32.8)$ & \\
\hline Education grade $\geq$ university (n [\%]) & $125.0(41.0)$ & $22.0(36.1)$ & NS \\
\hline
\end{tabular}

BMI, body mass index.

Abnormal acid exposure; $>4.5$ in $\%$ time of $\mathrm{pH}<4$ in total period.

Table 4. Multivariable Analysis: Relationship of Esophageal Acid Exposure With Gender, Smoking and Body Mass Index

\begin{tabular}{lccc}
\hline & \multicolumn{2}{c}{ Abnormal acid exposure $(+)$} \\
\cline { 2 - 4 } & Unadjusted OR $(95 \% \mathrm{CI})$ & $P$-value & Adjusted OR $(95 \% \mathrm{CI})$ \\
\hline Male gender & $2.94(2.44-3.56)$ & $<0.005$ & $2.23(1.17-4.22)$ \\
Current smoker & $2.83(1.76-4.55)$ & $<0.005$ & $1.46(0.75-2.81)$ \\
BMI & $1.67(1.52-1.84)$ & $<0.005$ & $1.41(1.02-1.95)$ \\
\hline
\end{tabular}

BMI, body mass index.

Abnormal acid exposure; $>4.5$ in $\%$ time of $\mathrm{pH}<4$ in total period.

Adjusted for gender, smoking and BMI. 
Table 5. Manometric Parameters in Patients With Gastroesophageal Reflux Disease

\begin{tabular}{lccccc}
\hline & $\begin{array}{c}\text { Underweight } \\
(\mathrm{n}=18)\end{array}$ & $\begin{array}{c}\text { Normal body weight } \\
(\mathrm{n}=152)\end{array}$ & $\begin{array}{c}\text { Overweight } \\
(\mathrm{n}=104)\end{array}$ & $\begin{array}{c}\text { Obesity } \\
(\mathrm{n}=92)\end{array}$ & $\begin{array}{c}P \text {-value } \\
\text { LES pressure (mean } \pm \mathrm{SD}, \mathrm{mmHg})\end{array}$ \\
\hline $50.2 \pm 16.2$ & $51.3 \pm 16.6$ & $48.2 \pm 15.3$ & $48.6 \pm 17.9$ & $\mathrm{NS}$ \\
LES length (mean $\pm \mathrm{SD}, \mathrm{cm})$ & $4.77 \pm 0.67$ & $4.65 \pm 0.81$ & $4.36 \pm 0.61$ & $4.34 \pm 0.91$ & $<0.005$ \\
Intraabdominal LES (mean $\pm \mathrm{SD}, \mathrm{cm})$ & $1.31 \pm 0.42$ & $1.22 \pm 0.39$ & $1.25 \pm 0.38$ & $1.32 \pm 1.18$ & $\mathrm{NS}$ \\
Gastroesophageal pressure gradient & $6.20 \pm 1.20$ & $7.80 \pm 2.80$ & $7.90 \pm 2.70$ & $8.20 \pm 2.70$ & $<0.05$ \\
$\quad($ mean $\pm \mathrm{SD}, \mathrm{mmHg})$ & & & & & \\
\hline
\end{tabular}

LES, lower esophageal sphincter.

\section{Discussion}

We retrospectively reviewed the data for 24 -hour $\mathrm{pH}$ monitoring and esophageal manometry of patients with suspected GERD to assess whether obesity is associated with increased esophageal acid exposure. We found a significant positive association between BMI and esophageal acid exposure. Our findings support the notion that obesity plays an important factor in GERD. The mechanism responsible for the relationship between GERD and obesity may be associated with shortening of the LES length and increasing of the GEPG.

Several Western studies have shown that obesity increases acid reflux. In a cross-sectional study of 206 patients, El-Serag et al. demonstrated that obesity was associated with a significant increase in acid reflux episodes, long reflux episodes ( $>5 \mathrm{mi}-$ nutes), time of $\mathrm{pH}<4$, and DeMeester score. ${ }^{11}$ These significant associations were seen in the total, postprandial, upright, and supine $\mathrm{pH}$ measurements. Crowell et al. found similar findings over 48 hours of wireless $\mathrm{pH}$ monitoring in 147 subjects. ${ }^{12}$ Acid exposure times during the day and night, number of acid reflux episodes, and longest episodes of esophageal acidification were significantly greater in obese subjects compared with overweight and normal weight individuals. Stacher et al. reported a positive correlation between $\mathrm{BMI}$ and esophageal acid reflux only in the upright period. ${ }^{18}$ Combined $\mathrm{pH}$ impedance monitoring also showed that both acid reflux episodes and nonacid reflux episodes increase significantly as BMI increases. ${ }^{19}$ In our study, significant associations were seen in the total, postprandial, and upright measurements, but not in the supine $\mathrm{pH}$ measurements. This may be explained by the small number of patients with pathological reflux in the supine period enrolled in this study.

Western studies define obesity as a BMI $\geq 30 \mathrm{~kg} / \mathrm{m}^{2}$ and have usually compared GERD between obese people and those with a BMI $<25 \mathrm{~kg} / \mathrm{m}^{2}$. In contrast to Western countries, there are fewer obese patients and morbid obesity is rare in Korea. In our study, only one-fourth of patients were classified as obese, defined as $\geq 25 \mathrm{~kg} / \mathrm{m}^{2}$ according to the Asia-Pacific criteria. Moreover, only $1 \%$ of patients had a BMI $>30 \mathrm{~kg} / \mathrm{m}^{2}$, the Western criterion for obesity. Despite the rarity of obesity in Korea, there was a linear trend between BMI and increased acid exposure, suggesting that obesity plays an important role in GERD.

How the pathophysiological mechanisms underlying obesity contribute to GERD is still not clear. Recent studies suggest that central or abdominal obesity, as measured by the waist-to-hip ratio, may be more important than general obesity, as measured by $\mathrm{BMI}^{20}$ A study using high-resolution manometry found that the pressure morphology within and across the esophagogastric junction is altered in a way that promotes GERD in obesity. ${ }^{9}$ In particular, during the inspiratory phase of respiration, increased intragastric pressure and the GEPG correlated strongly with BMI. Our study also demonstrated that the shorter LES length and greater GEPG were observed in obese patients. There was a linear trend showing that the higher the BMI, the shorter the LES length and the greater the GEPG. These relationships suggest that central obesity can raise intragastric pressure, causing predisposition for reflux. The other possible mechanisms by which obesity plays a role in the development of GERD are through the development of a hiatal hernia ${ }^{9,14}$ or shorter intra-abdominal LES length. ${ }^{15}$ An association between an increased frequency of transient LES relaxation and increased acid exposure has been reported in obese patients. ${ }^{10}$

There were some limitations in this study. First, it was a retrospective study. Second, cases with endoscopically confirmed GERD usually did not undergo $\mathrm{pH}$ monitoring, which prevented them from being included in this study. Third, as this study was carried out at a tertiary referral hospital, the result cannot be generalized. In addition, obesity was evaluated only by body mass index in this study. Several studies reported the associ- 
ation between obesity measured by other parameter such as abdominal diameter, waist to hip ratio and GERD.

In summary, we found that obesity is associated with increased acid reflux in Korean patients with GERD. The positive relationship between BMI and acid reflux parameters underscores the role of obesity in the pathophysiology of GERD and the possible benefits of weight reduction in the management of GERD. Shortening of the LES and increases in the GEPG may be underlying factors contributing to the increase in acid exposure. Our study supports a causal relationship between obesity and GERD in Asian patients. Further research is required to explore obesity as a pathophysiological mechanism related to GERD. It is also worthy to explore whether weight loss improves GERD. $^{21}$

\section{References}

1. Cho YS, Choi MG, Jeong JJ, et al. Prevalence and clinical spectrum of gastroesophageal reflux: a population-based study in Asan-si, Korea. Am J Gastroenterol 2005;100:747-753.

2. Youn YH, Kang YW, Ahn SH, Park SK. [Prevalence alteration of reflux esophagitis in recent years.] Korean J Gastrointest Endosc 2001;23:144-148. [Korean]

3. Lee JY, Hong WK, Sohn KM, et al. [Prevalence and clinical characteristics of gastroesophageal reflux disease and reflux esophagitis in chuncheon city- Health care examination study.] Korean J Med 2008;74:385-390. [Korean]

4. Jung SA, Jung HY, Kim KR, Min YI. [The prevalence of reflux esophagitis of Korean adults for 10 years of 1990's.] Korean J Gastrointest Motil 2001;7:161-167. [Korean]

5. Kang HS, Nam SW, Lee SE, et al. [The prevalence of Gastroesophageal Reflux Disease Associated with Age and Body Mass Index in Healthy Koreans.] J Korean Geriatr Soc 2008;12:201-206. [Korean]

6. Nam SY, Choi IJ, Nam BH, Park KW, Kim CG. Obesity and weight gain as risk factors for erosive oesophagitis in men. Aliment Pharmacol Ther 2009;29:1042-1052.

7. Nilsson M, Johnsen R, Ye W, Hveem K, Lagergren J. Obesity and estrogen as risk factors for gastroesophageal reflux symptoms. JAMA 2003;290:66-72.
8. Lagergren J, Bergström R, Nyrén O. No relation between body mass and gastro-esophageal reflux symptoms in a Swedish population based study. Gut 2000;47:26-29.

9. Pandolfino JE, El-Serag HB, Zhang Q, Shah N, Ghosh SK, Kahrilas PJ. Obesity: a challenge to esophagogastric junction integrity. Gastroenterology 2006;130:639-649.

10. Wu CJ , Mui LM, Cheung CM, Chan Y, Sung JJ. Obesity is associated with increased transient lower esophageal sphincter relaxation. Gastroenterology 2007;132:883-889.

11. El-Serag HB, Ergun GA, Pandolfino J, Fitzgerald S, Tran T, Kramer JR. Obesity increases oesophageal acid exposure. Gut 2007;56:749-755.

12. Crowell MD, Bradley A, Hansel S, et al. Obesity is associated with increased 48-h esophageal acid exposure in patients with symptomatic gastroesophageal reflux. Am J Gastroenterol 2009;104:553-559.

13. Ronnie Fass. The pathophysiological Mechanism of GERD in the Obese Patient. Dig Dis Sci 2008;53:2300-2306.

14. Fornari F, Madalosso CA, Farré R, Gurski RR, Thiesen V, Callegari-Jacques SM. The role of gastro-oesophageal pressure gradient and sliding hiatal hernia on pathological gastro-oesophageal reflux in severely obese patients. Eur J Gastroenterol Hepatol 2010;22: 404-411.

15. De Vries DR, Van Herwaarden MA, Smout AJ, Samsom M. Gastroesophageal pressure gradients in gastroesophageal reflux disease: relations with hiatal hernia, body mass index, and esophageal acid exposure. Am J Gastroenterol 2008;103:1349-1354.

16. Wilson LJ, Ma W, Hirschowitz BI. Association of obesity with hiatal hernia and obesity. Am J Gastroenterol 1999;94:2840-2844.

17. Jamieson JR, Stein HJ, DeMeester TR, et al. Ambulatory 24-h esophageal $\mathrm{pH}$ monitoring: normal values, optimal thresholds, specificity, sensitivity, and reproducibility. Am J Gastroenterol 1992;87: 1102-1111.

18. Stacher G, Lenglinger J, Eisler M, et al. Esophageal acid exposure in upright and recumbent postures: roles of lower esophageal sphincter, esophageal contractile and transport function, hiatal hernia, age, sex, and body mass. Dig Dis Sci 2006;51:1896-1903.

19. Hajar N, Castell DO, Ghomrawi H, Rackett R, Hila A. Impedance $\mathrm{pH}$ confirms the relationship between GERD and BMI. Dig Dis Sci 2012;57:1875-1879.

20. Corley DA, Kubo A, Zhao W. Abdominal obesity, ethnicity and gastro-esophageal reflux symptoms. Gut 2007;56:756-762.

21. Jacobson BC, Somers SC, Fuchs CS, Kelly CP, Camargo CA Jr. Body-mass index and symptoms of gastroesophageal reflux in women. N Engl J Med 2006;354:2340-2348. 